\title{
It is Never too Late to Learn: The Role of Physical Exercises in the Learning Process among the Older Adult Population
}

\author{
Glaucia Salgado, David Kaufman \\ Simon Fraser University, Canada
}

\begin{abstract}
Physical exercises are known as a great method for improving overall health. Recent research suggests that physical exercises are beneficial to improve memory and other cognitive processes [8], [43]. Learning is a critical aspect in the lives of individuals because it does promote not only knowledge but also fosters quality of life. As the number of older adults will continue to rise through the next years, these data are suitable to support future interventions to increase active life expectancy within financial constraints among governments, especially those that provide public health care.
\end{abstract}

\section{Introduction}

The 2019 Revision of World Population prospects shows that worldwide by 2050 , one in six individuals will be people in the age range of 65 and older. This proportion is even greater in European and North American countries where projections indicate that one in four people living in these areas will be older adults. A similar trend is observed in South America, Asia and Africa. Although there is great variation related to older age classification across nations with developed countries classifying older adults as those who are 65 years old and over, and in developing countries defining older people as those who are either 55 or 60 years old and over, older age has become a critical topic in health policies. Based on the increase in the population, there are limited options to help older adults stay connected and active in society [12]. This fact is critical because as the number of this population increases, the need to offer programs that can help older adults to maintain a healthy body and mind also increases. With this concern in mind, this research focused on searching articles from five electronic databases, including Angeline, Psych Info, ERIC (EBSCO), Sage Research Methods Online, and Cochrane Central. The keywords used were ageing, older adults, physical exercises, and learning. After analyzing titles and abstracts of over 3,000 articles, 59 were selected. While many articles strongly emphasize the importance of physical exercises to foster the learning process among older adults, others also suggest that the combination of physical exercises and learning can decrease social isolation, depression and improve quality of life [34], [41].

Some argue that services that can potentially be beneficial to older adults are related to learning activities [6], [20], [57]. Congruently to this fact, studies indicate that older adults are interested in learning programs, and this type of activity is often mentioned as one that promotes successful ageing. Learning is a process that happens when people engage in studies or is taught content that results in new or modified knowledge, skills, behaviours, attitudes, values and preferences. Also, learning occurs as a result of lived experiences [2], [44]. Lower education and illiteracy are associated with a higher risk of disability and poorer health outcomes among older adults. Hence, opportunities to engage in life-long learning activities facilitate the development of self-confidence, decision-making, sense of control, and skills older adults need in order to adapt and stay independent as the ageing process develops over time [7], [58]. In turn, more adapted and healthy older adults foster the disability-free life expectancy that can lower healthcare expenses caused by disability issues that may affect older adults [57]. Besides maintaining mental and physical health, learning activities are shown to be among older adults' interests, for it can help them to stay connected to society preventing critical issues related to isolation [30]. Also, learning can support many aspects of individuals' life; for instance, maintaining cognitive functioning, health management, and social relationships.

Moreover, learning might increase the socioeconomic status and well-being of older adults [9]. Although some cognitive processes might change as one age; for instance, it becomes harder to block irrelevant information during the learning process, and reaction-time slows down, given the opportunity, encouragement, and enough time older adults can successfully learn new skills, concepts and knowledge [39], [8]. Also, studies examining ageing and cognitive processes show evidence that individual differences within and between age groups in learning ability are often associated with personality traits and life habits [29],[35], [59].

It is critical to note that previous studies on agerelated changes suggested brain volume and weight declines during the ageing process. This view was strongly based on the assumption that the brain would lose neurons resulting in reduced learning 
capacity among older adults. However, finds indicate that the mean number of neurons of the cerebral cortex of men and women between the ages of 20 and 110 does not change [26]. A study suggests that what happens as one age is that the nerve cell body and synaptic density in some regions of the brain might suffer some decrease. However, this fact might not be directed related to ageing, but to the quality of neural development during the young years of life [3]. One needs to be reminded that the ageing "is a fundamental biological process that can be defined, measured, described and manipulated"; therefore, as one age, many changes might not be related simply to the ageing process, but the lifestyle, and some influences of the environment [3]. The Nun Study noted that more mentally, and physically active nuns had fewer issues with declines in brain processes, and even those who had some physical alterations in the brain, known as dementia-related characteristics; for instance, the amyloid plaques, had not shown cognitive changes due to the ageing process [45].

Changes in the cognitive function associated with the ageing process might affect reaction time and attentional capacity. A study comparing reaction time between young and older adults suggest that young adults process information more rapidly than older adults; however, this variation only implies that older adults need more time to execute a learning activity that does not necessarily interfere with older adults learning ability and capacity. Also, older individuals use different strategies than younger adults for problem-solving [56]. "It might take longer to remember some things or to solve complex problems, but the power to think remains the same" [36]. The attentional capacity - the ability "to maintain a goal-oriented behaviour when there are multiple other competing distractions" - undergo modifications as people get older. Generally, it has been observed that older adults have more difficulty ignoring other perceivable information. Hence, when older adults engage in learning a new task or information, besides allowing more time, it is beneficial to provide an environment that has fewer distractions [38], [56]. Also, learning does not happen in a vacuum; contrary, it occurs within a social context that encompasses cognitive and emotional processes. Learning involves a complex interplay between biological, emotional and social factors [28]. Finally, most declines in cognitive functions are triggered by lack of practice, illnesses, behavioural and social factors, so learning activities can support healthy cognitive function preventing cognitive declines as people age [7].

\section{Physical exercises and the brain}

Physical exercises are planned, designed, and repetitive set of body movements that will cause energy expenditure and has a goal to improve health or skill-related activity [11]. It is critical to distinguish physical exercise from physical activities as the latter is defined as any movement performed by the skeletal muscles of one's body in which results in energy expenditure; for instance, walking to the supermarket or doing the dishes [11]. Physical exercises are known to be a great method of improving physical and mental health. Many studies show that individuals who engage in physical exercises have less risk of developing certain types of illnesses such as diabetes and metabolic syndrome. Also, physical exercises have been used as an additional form of therapy to decrease symptoms of depression [13], [42]. Besides the fact that physical exercises can ameliorate several functional capacities in the human body, it is also considered beneficial to improve memory and other cognitive processes [8], [25], [43].

Research suggests that lifestyle factors like the practice of physical exercises might be closely related to the improvement of learning and memory on all individuals, especially older adults [37]. A meta-analyze study conducted to verify the effects of physical exercises in the cognitive processes found that sustained aerobic physical exercises can enhance the executive process of the brain [14]. Executive processes refer to operations responsible for coordinating mental activity in order to achieve a particular goal. It includes working memory, reasoning, problem-solving, planning and execution [56]. Different routines of exercises, intensity and duration consistently show improvements in acquisition and retention of new information in older adults [15], [51].

Moreover, exercises may protect the brain against atrophy in certain areas important for the learning process [14], [51], [55]. A study shows that moderate physical exercises like walking are positively associated with larger hippocampal volume in older adults. Good memory ability, lower risk of memory decline and dementia have been liked to larger hippocampus size [52].

\section{Influences of exercises in the hippocampus}

Although a full understanding of the underlying factors between physical exercises and the brain is still under investigation, some studies suggest that higher cardiorespiratory fitness, neurogenesis and angiogenesis are involved with the benefits associated with learning. Cardiorespiratory fitness refers to the circulatory and respiratory systems' ability to supply enough oxygen to the skeletal muscle system during sustained physical exercises. Besides stimulating these systems to work more efficiently, physical exercises increase the amount of oxygen that is inhaled, enabling more blood that, in this case, is rich in oxygen to distribute blood to all 
body systems, including the brain. Older adults who show higher cardiorespiratory fitness also show increased grey matter volume which results in better cognitive performance [54]. The literature suggests that high cardiorespiratory fitness influences neurogenesis and angiogenesis, factors related to cognitive performance and learning improvement. Neurogenesis refers to the process by which new neuron cells are produced in the brain, and angiogenesis is the new blood vessel formation from pre-existing vessels. For many years, researchers believed that neurogenesis was not possible to occur since neurons would only be generated before birth and would never change after birth [3]. Although most of the neurons in the human brain are indeed generated before birth, new studies show that neurogenesis occurs across the lifespan [17].

Other studies also indicate the positive relationship between physical exercise and neurogenesis. Findings show that exercises may be one of the conditions that induce neurogenesis. The study reveals that the practice of aerobic exercises is associated with increased hippocampal volume in older women with mild cognitive impairment [10]. This finding is consistent with another study by Erickson and colleagues [19] showing that healthy older adults who went to the intervention program of aerobic physical exercises for 12 months had a significant increase in the hippocampal volume as a result of neurogenesis.

\section{Chemical factors associated with physical exercises and brain function}

At least two growth factor proteins BDNF (brainderived neurotrophic factor) and VEGF (vascular endothelial-derived growth factor), and one hormone IGF-1 (insulin-like growth factor) are believed to contribute to neurogenesis enhancing the learning process. BDNF promotes the growth, development, and maintenance of neurons. Also, BDNF plays an active role in brain processes by regulating synaptic plasticity that is crucial for learning and memory [4], [23], [33], [47]. VEGF is produced by cells that stimulate new blood cell formation, angiogenesis [27].

The IGF-1 is an essential anabolic hormone that the body uses for the regulation of many physiological functions; for instance, the skeletal muscle function, neuronal activity and cognitive function [3], [31]. Furthermore, BDNF and IGF-1 "are crucial mechanisms underlying improved learning response to exercise" [15]. IGF-1 and VEGF are considered exercise-induced and seem to coordinate and stimulate neurogenesis and angiogenesis, respectively [21], [48].

In addition, some studies indicate that IGF-1 might be related to important neurodegenerative diseases such as Alzheimer's disease (AD). AD is a serious illness that impairs cognition, memory, and many other brain functions (Alzheimer's Association, n.d.). IGF-1 pathway disruption is associated with $\mathrm{AD}$, which shows the importance of IGF-1 and its relationship with cognitive processes [50]. Moreover, IGF-1 disturbances are connected to insulin problems. Gasparini and $\mathrm{Xu}$ [22] suggest that patients with Alzheimer's disease have a defective response to insulin-related to alterations in the IGF-1 and insulin level. This alteration might cause problems in the clearance of an important substance called beta-amyloid. Beta-amyloid is considered one of the key factors in the development of Alzheimer's disease, and its regulation appears to be strongly dependent on the levels of insulin and IGF-1 [3], [46]. High levels of insulin seem to disrupt the betaamyloid breakdown, while low levels of IGF-1 disturb the clearance of beta-amyloid cells [24], [40], [32]. Hence, IGF-1 plays a critical role in certain brain mechanisms that maintain a healthy brain. Due to the strong relationship between physical exercises and IGF-1 and insulin regulation might be one of the key factors that induce the production of IGF-1. It is essential to note that the relationship between physical exercises and the production of IGF-1 and VEGF has been established on experiments in which IGF-1 and VEGF were blocked. This process prevented the exercise-induced effects in the brain. Interestingly, studies show that older individuals who adhere to the practice of physical exercises have a lower risk of developing Alzheimer's disease and other cognitive problems [5]. The fact that these biological chemicals are critical to the neurological function demonstrates their role in learning. Furthermore, the evidence showing that these substances might be exercise-induced demonstrate the important role of keeping a lifestyle that involves the practice of physical exercises. In addition, these findings show that older adults maintain their learning capacity, which can be even improved due to exercises.

\section{Limitations}

The articles reviewed for this study do not show specific information about the ideal duration of exercise per session and for how long one needs to be engaged in constant physical activity to show improvements in the learning process. Also, there are other factors related to learning like the level of education and socioeconomic status among older adults, which should be examined in order to have more information about the influence of these factors among older adults who engage in physical exercises to improve the learning process. 


\section{Conclusion}

The increasing number of older adults in the population, circumstances related to cognitive decline, and older adults' desire to maintain social roles raise the attention to find ways to increase and promote learning. Although changes in cognitive functioning may accompany the ageing process, they are greatly associated with lifestyle and environment that lack elements to promote brain function. Older adults maintain their learning capacity, and methods like physical exercises might be beneficial to cognitive processes that can foster not only a healthier body but also a healthier mind. Furthermore, older adults who practice physical exercises might be at lower risk for certain serious diseases such as Alzheimer's disease. Promoting a healthier ageing process through physical exercises might increase the disability-free life expectancy, which in turn can lower the costs to both individuals and the healthcare system.

\section{References}

[1] Alzheimer's Association. (n.d). What is Alzheimer's. http://www.alz.org/alzheimers_disease_what_is_alzheimer s.asp

[2] Ambrose, S. A., Bridges, M. W., DiPietro, M., Lovett, M. C., \& Norman, M. K. (2010). How learning works: Seven research-based principles for smart teaching. John Wiley \& Sons. https://firstliteracy.org/wp-content/uploads/ 2015/07/How-Learning-Works.pdf.

[3] Arking, R. (2006). The biology of aging: observations and principles. Oxford University Press.

[4] Ahlskog, J. E., Geda, Y. E., Graff-Radford, N. R., \& Petersen, R. C. (2011). Physical exercise as a preventive or disease-modifying treatment of dementia and brain aging. In Mayo Clinic Proceedings, 86(9), pp. 876-884). https://doi.org/10.4065/mcp.2011.0252.

[5] Baker, L. D., Frank, L. L., Foster-Schubert, K., Gree, P. S., Wilkinson, C. W., McTiernan, A., Cholerton, B. A., Plymate, S. R., Fishel, M. A., Watson, G. S., Duncan, G. E., Mehta, P. D., Craft, S. (2010). Aerobic exercise improves cognition for older adults with intolerance: a risk factor for Alzheimer's disease. Journal of Alzheimer's disease, 22, 569 - 579. http://doi: 10.3233/JAD-2010100788.

[6] Benbow, S. M. (2009). Older people, mental health and learning. International psychogeriatrics, 21(5), 799-804. https://doiorg.proxy.lib.sfu.ca/10.1017/S104161020900905 3.

[7] Bennett, I. J., Madden, D. J., Vaidya, C. J., Howard Jr, J. H., \& Howard, D. V. (2011). White matter integrity correlates of implicit sequence learning in healthy aging. Neurobiology of Aging, 32(12), 2317-e1. https://doi.org/ 10.1016/j.neurobiolaging.2010.03.017.
[8] Bherer, L., Erickson, K. I., \& Liu-Ambrose, T. (2013). A review of the effects of physical activity and exercise on cognitive and brain functions in older adults. Journal of aging research, 2013. https://doi.org/10.1155/2013/6575 08 .

[9] Boulton-Lewis, G., Tam, M. (2012). Active ageing, active learning: issues and challenges. Dordrecht: Springer.

[10] Brinke, L. F., Bolandzadeh, N., Nagamatsu, L. S., Hsu, C. L., Davis, J. C., Miran-Khan, K., Liu-Ambrose, T. (2015). Aerobic exercise increase hippocampal volume in older women with probable mid cognitive impairment: a 6-month randomised controlled trial. British Journal of Sports Medicine, 49, 248-254. http://doi: 10.1136/bjsports-2013-093184.

[11] Caspersen, C. J., Powell, K. E., \& Christenson, G. M. (1985). Physical activity, exercise, and physical fitness: definitions and distinctions for health-related research. Public Health Reports,100(2),126-131. https://www.ncbi. nlm.nih.in/pmc/articles/PMC1424733/?tool=pmcentrez\&re port $=$ abstract.

[12] Chopik, W. J. (2016). The benefits of social technology use among older adults are mediated by reduced loneliness. Cyberpsychology, Behavior, and Social Networking, 19(9), 551-556. https://doi.org/10.1089 /cyber.2016.0151.

[13] Colberg, S. R., Sigal, R. J., Yardley, J. E., Riddell, M. C., Dunstan, D. W., Dempsey, P. C., ... \& Tate, D. F. (2016). Physical activity/exercise and diabetes: a position statement of the American Diabetes Association. Diabetes Care, 39(11), 2065-2079. https://doi.org/10.2337/dc161728.

[14] Colcombe, S. and Kramer, A.F. (2003). Fitness effects on the cognitive function of older adults: a meta-analytic study. Psychological Science, 14(2), 125-130. http://www.jstor.org.proxy.lib.sfu.ca/stable/40063782.

[15] Cotman, C. W., Berchtold, N. C., Christie, L. (2007). Exercise builds brain health: key roles of growth factor cascades and inflammation. Trends in Neuroscience, 30(9), 464-472. http://doi:10.1016/j.tins.2007.06.011.

[16] Cotterell, N., Buffel, T., \& Phillipson, C. (2018). Preventing social isolation in older people. Maturitas, 113, 80-84. https://doi.org/10.1016/j.maturitas.2018.04.014.

[17] Damásio, A. R. (1994). The Decartes' error: emotion, reason, and the human brain. Quill.

[18] Erickson, K., Prakash, R., Voss, M., Chaddock, L., Hu, L., Morris, K., White, S., Wojcicki, T., McAuley, E., Kramer, A., 2009. Aerobic fitness is associated with hippocampal volume in elderly humans. Hippocampus 19, 1030-1039. http:// doi: 10.1002/hipo.20547.

[19] Erickson, K., Voss, M., Prakash, R., Basak, C., Szabo, A., Chaddock, L., Kim, J., Heo, S., Alves, H., White, S., Wojcicki, T., Mailey, E., Vieira, V., Martin, S., Pence, B., Woods, J., McAuley, E., Kramer, A., 2011. Exercise training increases size of hippocampus and improves 
memory. Proc. Natl. Acad. Sci. U. S. A. 108, 3017-3022. https://doi.org/10.1073/pnas.1015950108.

[20] Escuder-Mollon, P., Esteller-Curto, R., Ochoa, L., \& Bardus, M. (2014). Impact on senior learners' quality of life through lifelong learning. Procedia-Social and Behavioral Sciences, 131, 510-516. http://doi: 10.1016/j.sbspro.2014.04.157.

[21] Fabel, K., Fabel, K., Tam, B., Kaufer, D., Balker, A., Simmons, N., Kuo, C. J., Palmer, T. D. (2003). VEGF is necessary for exercise-induced adult hippocampal neurogenesis. European Journal of Neuroscience, 18(10), 2803-2812. http://doi: 10.1111/j.1460-9568.2003.03041.x.

[22] Gasparini, L. and Xu, H. (2003). Potential roles of insulin and IGF-1 in Alzheimer's disease. Trends in Neuroscience, 26(8). http://doi:10.1016/S0166-2236(03) 00163-2.

[23] Genetics Home Reference. (2015). Genes. http://ghr.nlm.nih.gov/gene/BDNF.

[24] Giuffrida, M. L., Tomasello, F., Caraci, F., Chiechio, S., Nicoletti, F., \& Copani, A. (2012). Beta-amyloid monomer and insulin/IGF-1 signaling in Alzheimer's disease. Molecular neurobiology,46(3),605-613. https://do i-org.proxy.lib.sfu.ca/10.1007/s12035-012-8313-6.

[25] Hardman, A. E., Stensel, D. (2009). Physical activity and healthy: the evidence explained. Routledge Taylor \& Francis Group.

[26] Haug, H. and Eggers, R. (1991). Morphometry of the human cortex cerebri and corpus striatum during aging. Neurobiological Aging, 12(4), 336-338. https://doi:10.1016/0197-4580(91)90013-A.

[27] Hoeben, A., Landuyt, B., Highley, M. S., Wildiers, H., van Oosterom, A. T., Bruijn, E. A. (2004). Vascular endothelial growth factor and angiogenesis. Pharmacological Reviews, 56(4) 549 - 580. https://doi: 10.1124/pr.56.4.3

[28] Immordino-Yang, M. H. (2015). Emotions, learning, and the brain: Exploring the educational implications of affective neuroscience (the Norton series on the social neuroscience of education). WW Norton \& Company.

[29] Jackson, J. J., Hill, P. L., Payne, B. R., Roberts, B. W., \& Stine-Morrow, E. A. (2012). Can an old dog learn (and want to experience) new tricks? Cognitive training increases openness to experience in older adults. Psychology and Aging, 27(2), 286. https://doi.org/10.1037 la0025918.

[30] Jenkins, A., \& Mostafa, T. (2015). The effects of learning on wellbeing for older adults in England. Ageing \& society, 35(10), 2053-2070. https://doiorg.proxy. lib.sfu. $\mathrm{ca} / 10.1017 / \mathrm{S} 0144686 \mathrm{X} 14000762$.

[31] Kern, W., Born, J., Fehm, H. L. (2002). Role of insulin in Alzheimer's disease: approaches emerging from basic animal research and neurocognitive studies in humans. Drug Development Research, 56(3), 511 - 525. https://doi: 10.1002/ddr.10101.
[32] Kleinridders, A., Ferris, H. A., Cai, W., \& Kahn, C. R. (2014). Insulin action in brain regulates systemic metabolism and brain function. Diabetes, 63(7), 22322243. https://doi.org/10.2337/db14-0568.

[33] Kuipers, S.D. and Bramham, C.R. (2006). Brainderived neurotrophic factor mechanisms and function in adult synaptic plasticity: new insights and implications for therapy. Current Opinion in Drug Discovery \& Development, 9(5), 580-586.

[34] Lee, H. R., Šabanović, S., Chang, W. L., Hakken, D., Nagata, S., Piatt, J., \& Bennett, C. (2017, March). Steps toward participatory design of social robots: mutual learning with older adults with depression. In 2017 12th ACM/IEEE International Conference on Human- Robot Interaction (HRI (pp. 244-253). IEEE. https://doi.org/10. 1145/2909824.3020237.

[35] Lounsbury, J. W., Levy, J. J., Park, S. H., Gibson, L. W., \& Smith, R. (2009). An investigation of the construct validity of the personality trait of self-directed learning. Learning and Individual Differences, 19(4), 411-418. https://doi.org/10.1016/j.lindif.2009.03.001.

[36] Lowery, L. F. (1998). The biological basis of thinking and learning. California: The Regents of the University of California.

[37] Mandolesi, L., Polverino, A., Montuori, S., Foti, F., Ferraioli, G., Sorrentino, P., \& Sorrentino, G. (2018). Effects of physical exercise on cognitive functioning and wellbeing: biological and psychological benefits. Frontiers in psychology, 9, 509. https://doi.org/10.3389/ fpsyg.2018.00509.

[38] McAvinue, L. P., Habekost, T., Johnson, K. A., Kyllingsbæk, S., Vangkilde, S., Bundesen, C., \& Robertson, I. H. (2012). Sustained attention, attentional selectivity, and attentional capacity across the lifespan. Attention, Perception, \& Psychophysics, 74(8), 1570-1582. https://doi-org.proxy.lib.sfu.ca/10.3758/s13414-012-03526.

[39] McDaniel, M. A., Einstein, G. O., \& Jacoby, L. L. (2008). New considerations in aging and memory: the glass may be half full. In F. I. M. Craik \& T. A. Salthouse (Eds.), The handbook of aging and cognition (p. 251-310). Psychology Press.

[40] M de la Monte, S. (2012). Brain insulin resistance and deficiency as therapeutic targets in Alzheimer's disease. Current Alzheimer Research, 9(1), 35-66.

[41] Merriam, S. B., \& Kee, Y. (2014). Promoting community wellbeing: The case for lifelong learning for older adults. Adult Education Quarterly, 64(2), 128-144. https://doi.org/10.1177/0741713613513633.

[42] Mota-Pereira, J., Silverio, J., Carvalho, S., Ribeiro, J. C., Fonte, D., \& Ramos, J. (2011). Moderate exercise improves depression parameters in treatment-resistant patients with major depressive disorder. Journal of psychiatric research, 45(8), 1005-1011. 
[43] Nagamatsu, L. S., Chan, A., Davis, J. C., Beattie, B. L., Graf, P., Voss, M. W., ... \& Liu-Ambrose, T. (2013). Physical activity improves verbal and spatial memory in older adults with probable mild cognitive impairment: a 6month randomized controlled trial. Journal of Aging Research. https://doi.org/10.1155/2013/861893.

[44] Reichstadt, J., Sengupta, G., Depp, C. A., Palinkas, L. A., \& Jeste, D. V. (2010). Older adults' perspectives on successful aging: qualitative interviews. The American Journal of Geriatric Psychiatry, 18(7), 567-575. https://doi.org/10.1097/JGP.0b013e3181e040bb.

[45] Snowdon, D. A. (2003). Healthy aging and dementia: findings from the Nun Study. Annals of Internal Medicine, 139(5), 450 - $454 . \quad$ https://10.7326/0003-4819-1395_Part_2-200309021-00014.

[46] Suzanne, M. (2012). Contributions of brain insulin resistance and deficiency in amyloid-related neurodegeneration in Alzheimer's disease. Drugs, 72(1), 49-66. https://doi- org.proxy.lib.sfu.ca/10.2165/11597760000000000-00000.

[47] Talbot, K., Wang, H. Y., Kazi, H., Han, L. Y., Bakshi, K. P., Stucky, A., ... \& Arvanitakis, Z. (2012). Demonstrated brain insulin resistance in Alzheimer's disease patients is associated with IGF-1 resistance, IRS-1 dysregulation, and cognitive decline. The Journal of clinical investigation, 122(4), 1316-1338. https://doi.org/ 10.1172/JCI59903.

[48] Trejo, J.L., Carro, E., Torres-Alema, I. (2001). Circulating insulin-like growth factor I mediates exerciseinduced increases in the number of new neurons in the adult hippocampus. Journal of Neuroscience, 21(5), 16281634.https://doi.org/10.1523/JNEUROSCI.21-05-01628. 2001.

[49] United Nations (2019). World population prospects 2019. https://population.un.org/wpp/.

[50] Vaynman, S., Ying, Z., Gomez-Pinilla, F. (2004). Hippocampal BDNF mediates the efficacy of exercise on synaptic plasticity and cognition. European Journal of Neuroscience, 20(10), 2580-2590. https://doi: 10.1111/j. 1460-9568.2004.03720.x

[51] Voss, M. W., Weng, T. B., Burzynska, A. Z., Wong, C. N., Cooke, G. E., Clark, R., ... \& McAuley, E. (2016). Fitness, but not physical activity, is related to functional integrity of brain networks associated with aging. Neuroimage, 131, 113-125. https://doi.org/10.1016/j.neuro image.2015.10.044

[52] Varma, V. R., Chuang, Y. F., Harris, G. C., Tan, E. J., \& Carlson, M. C. (2015). Low-intensity daily walking activity is associated with hippocampal volume in older adults. Hippocampus, 25(5), 605-615.

[53] Vaynman, S., Ying, Z., Gomez-Pinilla, F. (2006). Exercise differentially regulates synaptic proteins associated to the function of BDNF. Brain Research. 1070(1),124-130. https://doi:10.1016/j.brainres. 2005. 11.062
[54] Weinstein, A. M., Voss, M. W., Prakash, R. S., Chaddock, L., Szabo, A., White, S. M., ... \& Erickson, K. I. (2012). The association between aerobic fitness and executive function is mediated by prefrontal cortex volume. Brain, behavior, and immunity, 26(5), 811-819. https://doi.org/10.1016/j.bbi.2011.11.008

[55] Weuve, J., Kang, J. H., Manson, J. E., Breteler, M. M. B., Ware, J. H., Grodstein, F. (2004). Physical activity, including walking, and cognitive function in older women. The Journal of the American Medical Association, 292(12), 1454-1461. https://doi:10.1001/jama.292.12.1454

[56] Whitbourne, S. K. and Whitbourne, S. B. (2014). Adult development and aging: biopsychosocial perspectives. (5th Ed.). Hoboken: Wiley-Blackwell.

[57] Wister, A. V. and McPherson, B. D. (2008). Aging as a social process: Canadian perspectives. Oxford University Press.

[58] World Health Organization (2002). Active ageing: a police framework. http://whqlibdoc.who.int/hq/2002/ WHO_NMH_NPH_02.8.pdf?ua=1.

[59] World Health Organization (2015). World report on ageing and health. https://apps.who.int/iris/bitstream/ handle/10665/186463/9789240694811_eng.pdf;jsessionid $=92 \mathrm{C} 7 \mathrm{FAC}$ FFF2E5019AE38F69985C01C31 ? sequence $=1$. 